\title{
Mitral valve repair based on physical characterization of coaptation forces
}

Daniel Grinberg, MD, MS, ${ }^{\mathrm{a}, \mathrm{b}, \mathrm{c}}$ Alexis Bruhat, MS, ${ }^{\mathrm{b}}$ Pierre-Jean Cottinet, $\mathrm{PhD},{ }^{\mathrm{c}}$ Minh Quyen Le, $\mathrm{PhD},{ }^{c}$

David H. Adams, MD, ${ }^{\mathrm{a}}$ and Anthony Costa, PhD, ${ }^{\mathrm{b}}$ New York, NY, and Villeurbane, France

From the Departments of ${ }^{\text {a Cardiovascular Surgery and }}{ }^{\mathrm{b}}$ Neurosurgery, Mount Sinai Hospital, New York, NY; and ${ }^{c}$ LGEF at INSA Université de Lyon, Villeurbane, France.

Supported by INSAVALOR BQI funding, Fédération Française de Cardiologie, Philippe Foundation, Foundation Servier, and The Mitral Foundation.

Disclosures: The Icahn School of Medicine at Mount Sinai receives royalty payments from Edwards Lifesciences and Medtronic for intellectual property related to development of valve repair rings. Dr Adams is national coprimary investigator of the Medtronic APOLLO FDA Pivotal Trial, the NeoChord ReChord FDA Pivotal Trial, The Medtronic CoreValve US Pivotal Trial, and the Abbott TRILUMINATE Pivotal Trial. All other authors have nothing to disclose with regard to commercial support.

Received for publication May 20, 2019; revisions received July 15, 2019; accepted for publication July 18, 2019; available ahead of print Oct 6, 2019.

Address for reprints: Daniel Grinberg, MD, MS, Sinai BioDesign Lab, Icahn School of Medicine at Mount Sinai, 1428 Madison Ave, BMC 24, New York, NY 10029 (E-mail: daniel.grinberg.pro@gmail.com).

J Thorac Cardiovasc Surg 2020;159:e181-3

$0022-5223 / \$ 36.00$

Copyright (C) 2019 by The American Association for Thoracic Surgery

https://doi.org/10.1016/j.jtcvs.2019.07.097

- Video clip is available online.

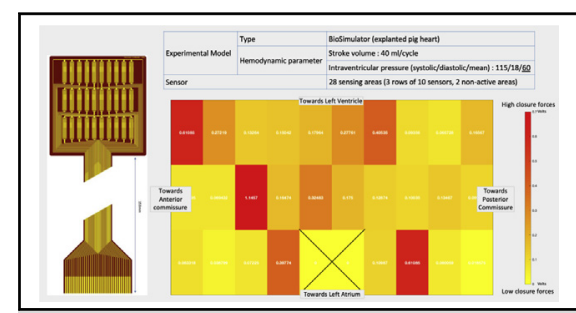

Measurement of coaptation forces and mapping of these forces in ex vivo beating hearts.

\section{Central Message}

Technological breakthrough allows surgeons to obtain a precise characterization of mitral valve coaptation (surface measurement and coaptation force mapping) to assist surgeons during mitral valve repair surgery.

See Commentaries on pages e185, e187, and e189.
Open surgical mitral valve repair (MVr) is the gold standard treatment for severe primary mitral regurgitation (MR). Several approaches have been set forth in prior literature to mimic ventricular systole intraoperatively, such as the saline solution test and the ink test. ${ }^{1}$ Such methods provide only a morphologic and approximate assessment. The success of an MVr procedure today thus still depends primarily on the expertise of the individual surgeon. Consequently, major heterogeneities are observed globally in MVr repair rates, surgical techniques, and outcomes. In Western countries, only 2 of 3 patients with primary MR benefit from $\mathrm{MVr}$, whereas the others are treated with an implanted prosthesis that is associated with worse outcomes. ${ }^{2}$

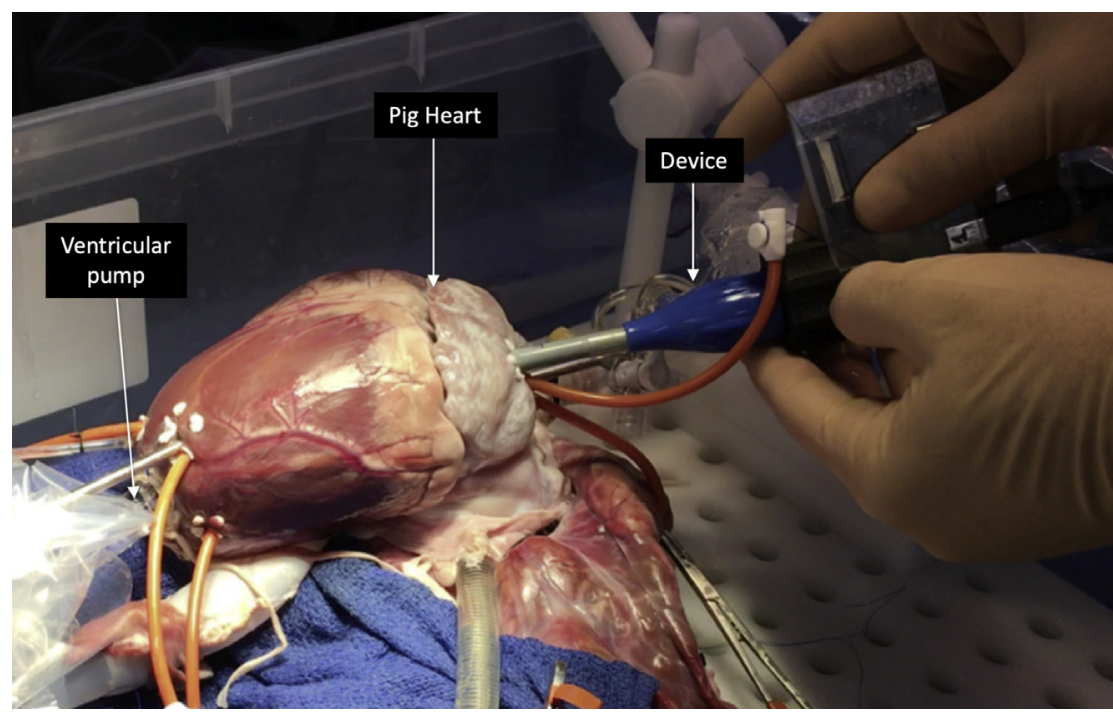

FIGURE 1. Testing on ex vivo beating heart model. The surgeon is holding the device, which was introduced through the posterior wall of the left atrium into the mitral valve. This ex vivo model is activated by an apical pump. 


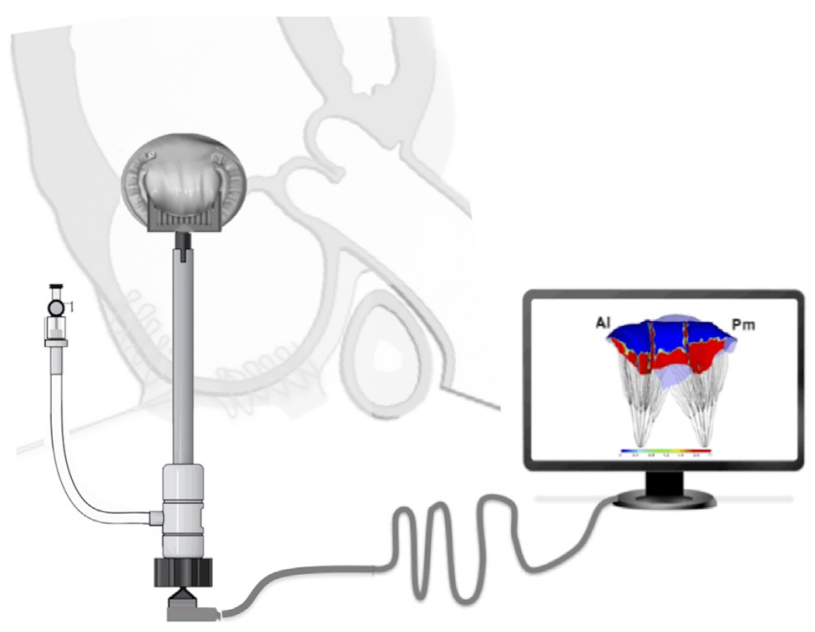

VIDEO 1. Rendering of mitral coaptation forces mapping in biosimulator model. Red colors correspond to high forces. Every colored rectangle corresponds to a sensing area. Video available at: https://www.jtcvs.org/ article/S0022-5223(19)31651-4/fulltext.

Furthermore, depending on the series, as many as $25 \%$ of patients will develop recurrent MR after $\mathrm{MVr}^{3}$ Among these patients, a large majority have no MR at discharge, highlighting the insufficient ability of echocardiography to predict midterm repair failure. ${ }^{4}$ New tools are required to enhance the understanding of the coaptation behavior and to assist surgeons to increase repair rate and longterm repair sucess.
The restoration of a large surface of coaptation is one of the key principles of mitral reconstruction, and a high coaptation height is correlated with lower postoperative residual MR. In a previous work, we developed an innovative technique to measure the tension applied on chordae during transapical beating-heart implantations of neochordae. Our results revealed a decrease in subvalvular apparatus stress when strong and homogeneous coaptation was restored. To date, coaptation forces have been poorly measured because of challenges in materials and device design (eg, compactness, flexibility, sensing accuracy), as well as deployment in complex clinical environments (eg, beating heart, coaptation zone).

In this work, we have developed a device that enables precise physical and quantitative characterization of the coaptation (eg, mapping of coaptation forces [perpendicular forces, one leaflet against the other] and measurement of coaptation surface). The tool is composed of 3 principal parts:

- A piezoresistive pressure sensor includes 28 strain gages made from resistive ink printed on a flexible polyimide substrate. Its design (total area of $5.8 \mathrm{~cm}^{2}$ and thickness of $150 \mathrm{~mm}$, composed of 28 individual $2-\mathrm{mm}^{2}$ sensing elements) provides easy insertion between the 2 leaflets without changing the natural 3-dimensional coaptation shape because of the low thickness and stiffness of the sensing element. During the measurement period, the sensor sits in the mitral valve orifice.

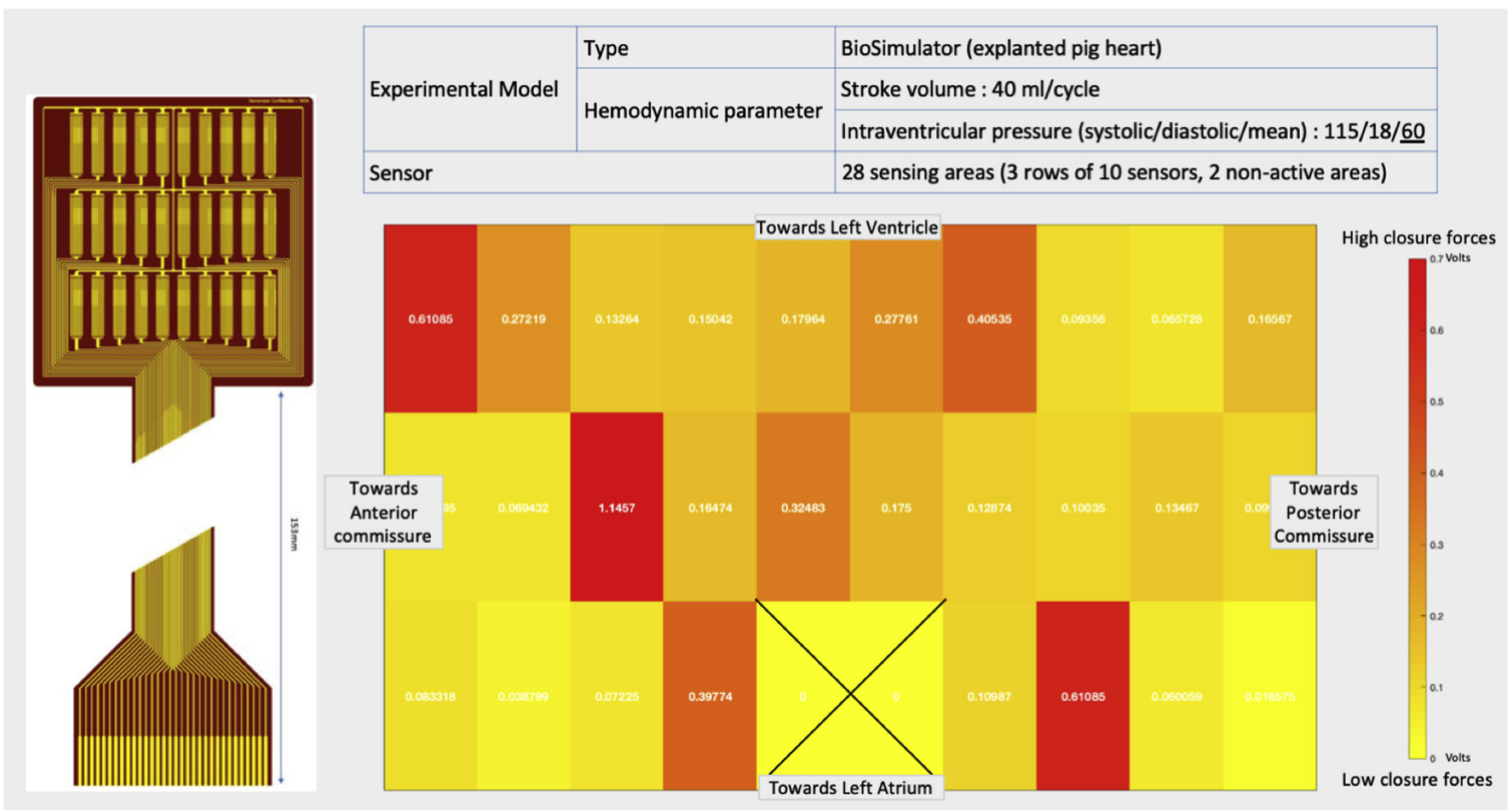

FIGURE 2. Design of the sensors used (left), and graphical render of mitral valve coaptation forces mapping (right). Red colors correspond to high forces. Every colored rectangle corresponds to a sensing areal of $1 \times 3 \mathrm{~mm}$. This mapping provides a 2-dimensional representation of pressure repartition. 


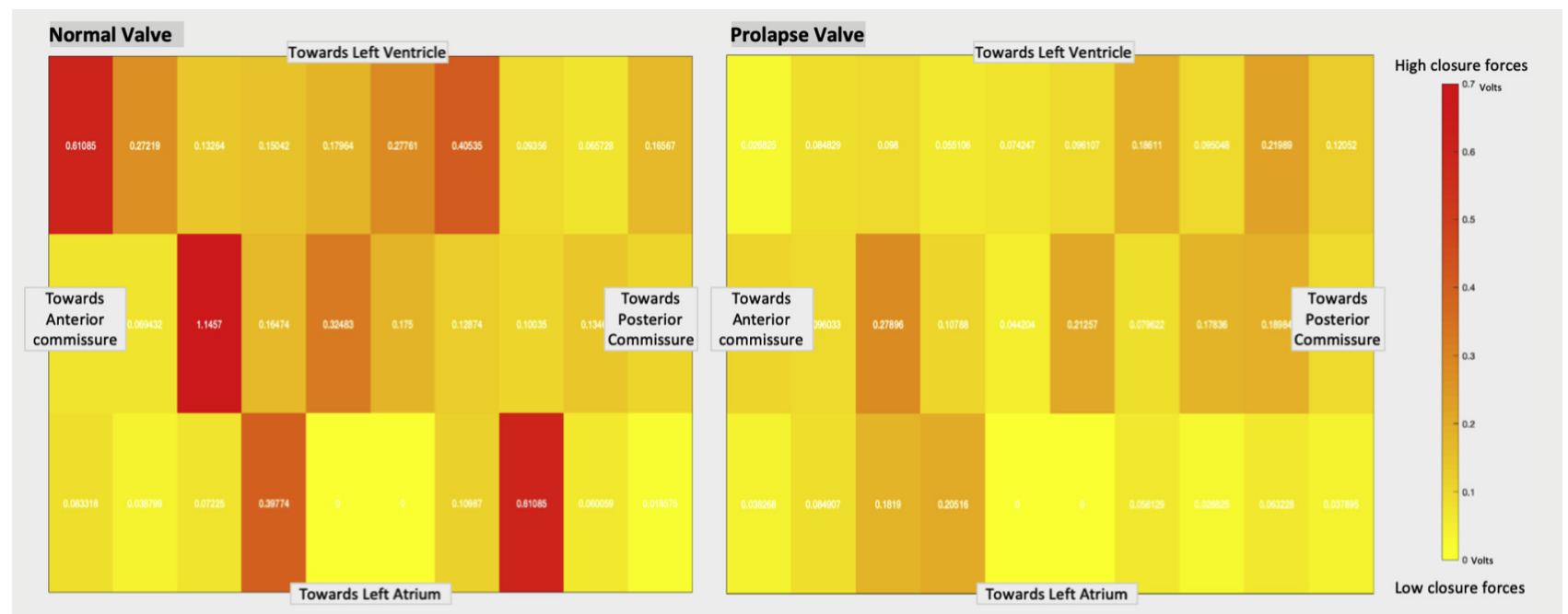

FIGURE 3. The mapping of forces was obtained in a normal valve (left) and in a prolapsed valve (right). A simple visual observation reflects higher coaptation forces in a normal valve than in a pathologic one.

- A support device (holder) enables easy maintenance of the sensor in the mitral valve and removal after measurement.

- An acquisition system that records and analyzes data in real time. The time domain of 28 signals is then posttreated with a Fast Fourier Transform. Frequency analysis of all data is performed in different conditions of mitral valves (normal or prolapsed).

The device is specifically designed for application to $\mathrm{MVr}$ procedures. It is inserted inside the heart through the left atriotomy (repair access) during the procedure and positioned between the 2 leaflets. The device can be kept in the heart when the atriotomy is closed, making continuous force measurements in a beating-heart state possible, and then removed before the closure of the chest without risk of air embolism.

The prototype has been iteratively tested on three porcine ex vivo total heart models activated by an apical pump (eg, biosimulator; Figure 1 and Video 1). Initial results achieved precise surface mapping of mitral valve coaptation forces (Figure 2). The coaptation signal was first recorded in a normal valve and then after creation of a posterior central prolapse (section of marginal chordae). We demonstrated that the forces recorded were notably higher in the normal valve than in the prolapsed one under similar hemodynamic conditions (Figure 3). Our tests also demonstrated the limitations of piezoresistive technology (noise from bending, loss of calibration), and indicated that our chosen biosimulator is not an ideal testing model for this measurement, because the pump ejection generated a functional MR as a result of annular dilatation.

A provisional patent based on our novel method has been filed. Further development of the device is in progress as we move our invention toward clinical trials: selection of optimal sensing technologies, optimization of force sensitivity, substrate flexibility, and biocompatibility. In the near future, this technique could be useful to assist surgeons during MVr while providing real-time, objective measurements in support of the conventional intraoperative morphologic assessment. Coaptation force characterization could also be useful to improve our understanding of physical changes occurring during primary MR development and after MVr.

\section{References}

1. Anyanwu AC, Adams DH. The intraoperative "ink test": a novel assessment tool in mitral valve repair. J Thorac Cardiovasc Surg. 2007;133:1635-6.

2. Chikwe J, Toyoda N, Anyanwu AC, Itagaki S, Egorova NN, Boateng P, et al. Relation of mitral valve surgery volume to repair rate, durability, and survival. J Am Coll Cardiol. 2017;69:2397-406.

3. Flameng W, Herijgers P, Bogaerts K. Recurrence of mitral valve regurgitation after mitral valve repair in degenerative valve disease. Circulation. 2003;107: 1609-13.

4. Gasser S, von Stumm M, Sinning C, Schaefer U, Reichenspurner H, Girdauskas E. Can we predict failure of mitral valve repair? J Clin Med. 2019;8:1-12.

5. Grinberg D, Cottinet P-J, Thivolet S, Audigier D, Capsal JF, Le MQ, et al. Measuring chordae tension during transapical neochordae implantation: toward understanding objective consequences of mitral valve repair. J Thorac Cardiovasc Surg. 2019;158:746-55. 